\title{
How Green Economy Contributes in Decreasing the Environment Pollution and Misuse of the Limited Resources?
}

\author{
Haga Elimam ${ }^{1}$ \\ ${ }^{1}$ King Abdulaziz University, KSA \\ Correspondence: Haga Elimam, King Abdulaziz University, KSA. E-mail: helimam@outlook.com \\ Received: January 8, 2017 \\ Accepted: January 24, $2017 \quad$ Online Published: March 8, 2017 \\ doi:10.5539/ep.v6n1p10 \\ URL: https://doi.org/10.5539/ep.v6n1p10
}

\begin{abstract}
Green economy has invested in the sustainable development of the society across the globe. Therefore, the study has focused on differential ways that green economy provided for the reduction of misusing limited resources along with the reduction of environmental pollution. Since, the study has been conducted on the global issue, the nature of the analysis would be qualitative. The data has been collected from the previous studies on green economy. The results have shown the different factors that affect the society, which included wastes, toxic gases, and the hazardous solvents ecologically as well as economically. The implementation of green chemistry was the solution provided to eliminate poverty and pollution from the society. In the years 1990 and 2010, the emissions of non-methane compounds were increased by $71 \%$ and decreased by $4 \%$. Whereas, the emissions of nitrogen oxides were increased by $62 \%$ and decreased by $3 \%$. Moreover, intelligent usage of limited resources have provided better ways to increase economic growth and reduce toxins from the atmosphere. Adoption of green economy in the countries can be useful on the economic and social grounds as they helped in decreasing the environment pollution and along with the misuse of limited resources.
\end{abstract}

Keywords: atmosphere, environment pollution, green economy, limited resources, toxins

\section{Introduction}

Green Economy is a common terminology, which is referred as the process that aims for sustainable development without degrading the environment. The term "green economy" has emerged globally over the recent years. Such economy was unfamiliar before 2008, but now it has occupied by the policies of international economic and developmental sectors for the sustainable growth of the economies (Jacobs, 2012). This is because the green economy has come up to provide a gateway towards justifiable development.

The world is facing serious environmental pollution and the exploitation of the limited resources to eradicate many aspects. The misuse of limited resources and the increased environmental pollution are gradually increasing among the global frontiers. Environmental factors and its exploitation resulted in decreasing the development of the country along with the eradication of poverty as well. Therefore, green economy can be considered as the best source for restoring growth, limiting climate changes, and to create employment opportunities. The way to approach the sustainable development is to focus on the past experiences and working for the improvement of water and agricultural management (Valipour, 2016a). Additionally, water and agricultural management have been poorly focused in the areas, which require water for irrigation purposes (Valipour, 2013a). The awareness of hydrological situations in different regions can aid to sympathetic planning for practical apportionment of agricultural water management and water resources (Valipour, 2013b; Valipour, 2013c). Moreover, the accurate estimation of the recurrent rainfall is considerably significant in crop pattern design and water resource management (Valipour, 2016b).

Nica (2015) emphasized upon the deep considerate of green economy, which would help to eliminate poverty and provide ways for development. Thus, the aim of this study was to examine the political economy of the development mechanisms. It targets to examine the influences of the green economy on labor markets, and also to study the functions of markets and countries for changes in green economy. From economic, social and environmental views, the global development pattern is groundless. In order to accumulate the green-house gases in the environment, considerable economic outlay is required. Demanding the green economy can provide help in eliminating the dangers of environmental pollution. The selection of proper drainage system can serve as the most beneficial factor in agricultural or other related fields (Valipour, 2012a; Valipour, 2012b). A reliable surface 
or pressurized irrigation can be enhanced by paying attention on irrigation efficiency and agricultural production (Valipour, 2013d). Future of agricultural water management can be estimated by focusing on the areas or land equipped for irrigation (Valipour, 2015a; Valipour, 2015b).

In order to create governance mechanisms and the institutes to force the world for adapting green economy, understanding of functioning of urban economy and its connection with the larger world (global, national, and regional) is an important factor. De Oliveira, et al. (2013) indicated that a country is analyzed on the basis of economic processes, changing of space, production and consumption, knowledge and ecosystem services. The implementation of green economy and its effects on the people and ecosystems were studied by providing the proposal of indicators used in the governance of assessing the green urban processes. These proposed approaches helped the country to decide beyond the limitations and helped to implement bigger changes, which results in greening the economy.

It was believed that different shapes and shades would be taken by the green economy. Green economy must be relevant to the people locally, which will help them to become prosperous and secure (Coalition, 2012). If the individuals become mentally empowered, they will help the industries and companies by providing the support in different natural and cultural contexts. In international collaboration, the people should be globally strong, so that they can enable markets to build the solutions at new inspirational scales. Therefore, it is said that the greener economies should improve natural systems and capitals along with human wellbeing to empower them globally, economically, and locally. This aspect can be achieved by collaborating with the environmental and growth ambitions. Thus, the study has aimed to provide differential ways that help in decreasing the misuse of limited resources and decreasing the environmental pollution. Similarly, the study would also contribute in the domain of science and technology, specifically related with the environment.

The study has precisely focused on prevailing the awareness about the advantages of having green economies in the region, which can be a great source of decreasing the misuse of the limited resources and environmental pollution. It also focused on the green economy and its related factors that can help to reduce the environmental pollution globally. The novelties of the current investigation lies in the factors that negatively affects the society and its reduction by promoting the green economy awareness to the affected regions. Former studies have focused on the green economies but the ways to reduce the misuse of the resources and enhancing the environmental situations were insufficient.

\section{Theoretical Foundation}

\subsection{Growth Theory}

It was observed that the natural environment has catered the concept of green growth establishment theory since a long period of time. The environment has served the base for green growth in three ways, which includes adapting wastes, delivering resources, and providing environmental services that mainly include ecosystem health and climatic regulation. This factor was being ignored by the practice and economic theories (Jacobs, 2012).

In the analysis of the green economy, Ocampo (2011) has highlighted four major issues. The first issue declared the effects, being occurred as the environmental degradation of aggregate supply and demand. Second issue reported that the process of structural change was the outcome of economic growth; it should keep its production and consumption in accordance with the green economy, which will be regarded as the new manufacturing and technical uprising. Third issue was related to the welfare, which pointed towards the growth of future generations by enhancing the economic status in the form of investments and savings. The final issue was related to the proper funding of these international initiatives. Ocampo (2011) has further stated that:

"Half a century back from now, $\$ 100$ were served in the environmental damage and today they are valued at $\$ 49.90$. Using the discount rate of Stern Review, which is $1.4 \%$ a year but only $\$ 5.43$ or $\$ 6.88$ using the alternative rates preferred by its critics (6 and $5.5 \%$ respectively)".

The findings also showed that the common profitability of taking justifications can be compact if the high discount rates are used. This aspect verified the third factor of the previously mentioned four factors that savings for today could be fruitful for the bright future ahead, in terms of economy.

\subsection{Countries in Transition to a Green Economy}

It has been reported by UN Environment, which has listed the development of seven countries that adopted the green economy. 


\subsubsection{Organic Agriculture in Uganda}

An organic farming system was established out of conventional and agricultural production. This aspect has resulted in achieving benefits for the society, environment, and economy of Uganda.

\subsubsection{Renewable Energy in China}

China was found investing into the green sectors, with the demand on energy efficiency and renewable energy. This share of investment was done by the 11th Five-year Plan (2006-2010). As compared to 2005, the per-unit GDP consumption of energy by the year 2010 should have decreased by $20 \%$ as projected by the plan. By 2020 , the Chinese government has made the commitment to reuse the energy from the primary resources and will be producing $16 \%$ of the primary energy out of renewable resources.

\subsubsection{Sustainable Urban Planning in Brazil}

Urban challenges have been overcome by the city of Curitiba, in Brazil over the last decades and served as an inspiration for the other cities in Brazil. Bus Rapid Transit system was the example of integration of industrial and urban planning that enabled the gates for industrial development and job opportunities.

\subsubsection{Forest Management in Nepal}

In Nepal, a central place is occupied by the community forests in forest management. Other involvements on the government side or the financial involvement were involved by the Forest management.

\subsubsection{Rural Ecological infrastructure in India}

In rural areas of India, a program named India's National Rural Employment Guarantee Act 2005 (NREGA) helped in enhancing the livelihood of people by providing the job opportunities. This helped people in rural areas for practicing a secure livelihood and get a good growth in economical areas.

\subsubsection{Solar Energy in Tunisia}

Tunisia has established a funding mechanism to improve efficiency of energy and to support the increased capacity in renewable energy technologies. This mechanism was named as the National Fund for Energy Management. The replacement of this fund is based on the major recording of petrol-powered, private and diesel powered cars, which are air-conditioned with the barring of those products for shipment.

\subsubsection{Ecosystem Services in Ecuador}

Together with a non-governmental organization in the year 2000, The Fund for the Protection of Water (FONAG) was founded. This was organized to have the contribution of water users in Quito. A study by Lean (2006) evaluated that assistance and advice have been requested by most of the governments about different ways to adapt a transition to a low carbon, within economic planning and development strategies. Moreover, Africa has been found working on the Green Economy Initiative for the preparation of the low carbon growth. Green economy studies have included the institutions of China in collaboration with the UNEP (United Nations Environment Programme). In the West Asian countries (Dubai, Bahrain, Kuwait, Saudi Arabia, Jordan, and Lebanon), the green economy sectors have been emerged as the catalogues. The adoption of regional environment work programme was predicted to be adopted by the year 2020 among West Asian countries. The terms Green Growth and Green Economy are gaining fame across the capital cities of the countries. From weather change to environmental losses, the determination of the challenges facing all economies become more outward. It is becoming apparent with every passing year because the need to overcome poverty and deliver the growth were the main issues faced by the countries. Green economy was the outcome to the major challenges, since it has emerged as the practical and powerful opportunity to eradicate poverty and environmental pollution. Moreover, the low-carbon development is evolving as the practical solution for today's global environmental challenge (Lean, 2006). 


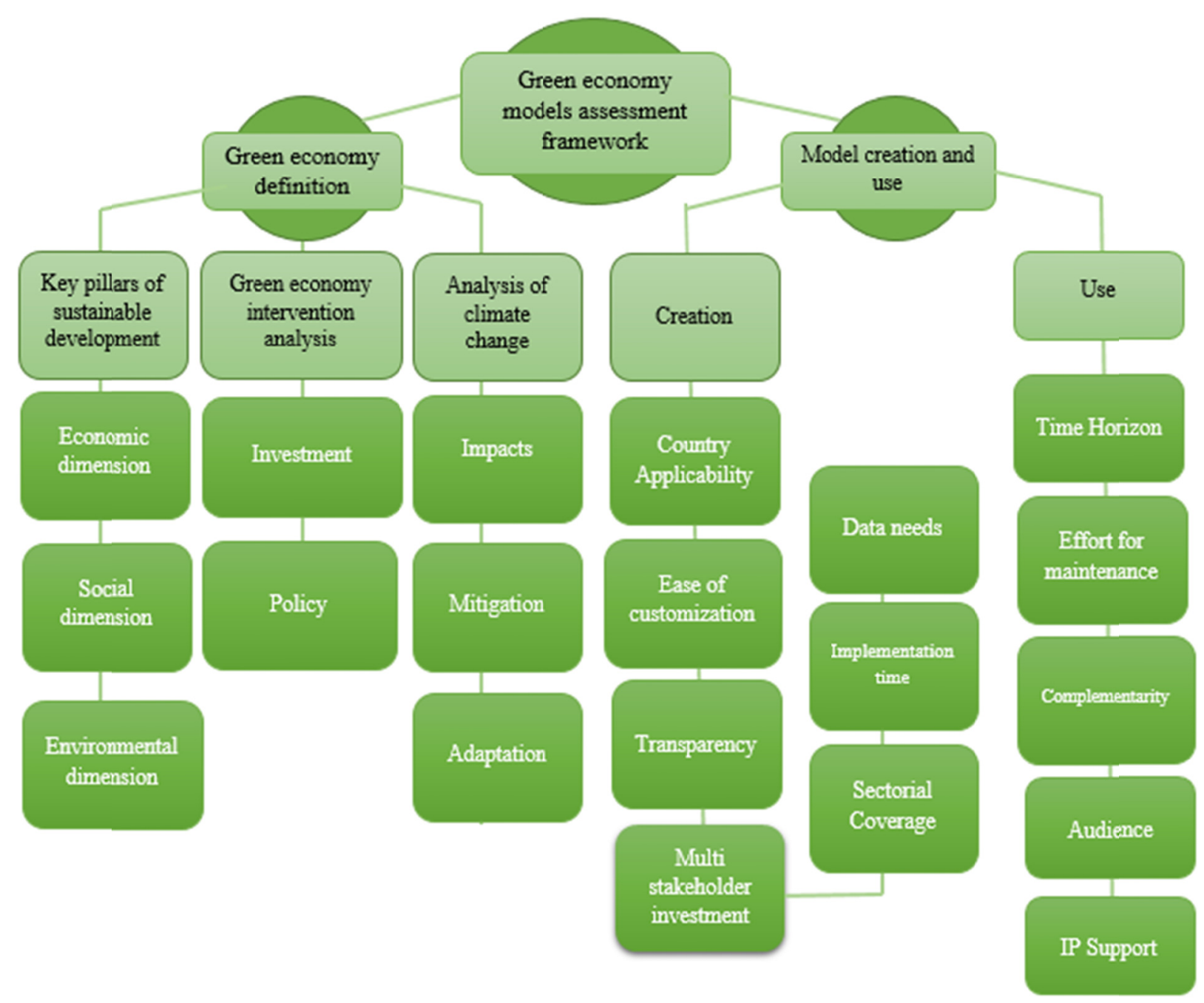

Figure 1. Process Model for green economy assessment framework

As shown in Figure 1, green economy model assessment framework is divided into two major categories; green economy definition and creation of model and its usage. Green economy definition is comprised of three main things; sustainable development, intervention analysis, and the analysis of climate change. Whereas, model is distributed in the creation and use. The overall model represented the environmental, social and economic problem dimensions that include natural, economic, and human principal in a single framework. Climatic changes have also been addressed and the contributions of green economy investment and policy analysis are discussed. Time, data, and the economic resources have been insufficient for the creation of model. Therefore, maintenance and implementation time, transparency, IP support and audience act as the main sources to overcome these challenges (UNEP, 2014).

\section{Methodology}

The study has opted a qualitative research approach to examine the contribution of green economy in decreasing the environment pollution. The source of data selection was done from reputed international journals. Online information was gathered from various sites, online libraries, and published books. The ERIC, JSE, ScienceDirect and Google Scholar provided a base line for the source of data collection. After developing the procedural norms to be followed, it was decided to make the use of the qualitative study design. The development of the green economy across the globe has been one of the most significant aims of the study; therefore, the past literature has been properly screened in terms of green economy performance and its usage in the reduction of environmental pollution. As for the theoretical background of the study, it is worth mentioning that several existing frameworks had been previously checked for their competency in the field. An extensive research had to be carried out to map the needs of the development of the green economy. Therefore, all of the 
measures have been used to cater the needs of the analysis and further identify the results.

\section{Results and Discussion}

The results of the study will be divided into the two main sections considering the objective of the study:

\subsection{Reduction of Environmental Pollution}

Environmental pollution includes intimidations in the form of solid wastes, atmospheric pollution, deforestation, acid rain, and desertification that play significant roles in the reduction of the ozone layer. The World Commission on Environment and Development of the United Nations was first established in 1987, which is known for the development of an idea of sustainable eco-development (Valavanidis, A. 2012). It has been evaluated that to engross pollution or waste and to refill natural resources, environmental footmark of humans is now $52 \%$ greater than the size of the planet (Coalition, G. E. 2012). It was recorded as the $6 \%$ more of the previous year, the increase in the global greenhouse gas emissions. Emissions of Sulphur dioxide: It has been observed that between the years 1990 and 2010 in UK, Sulphur dioxide emission was decreased by $89 \%$. Later, it was increased by $2 \%$ between 2009 and 2010. It was recorded $31 \%$ in the year 2010, which was underneath the deepest international board as shown in Figure 2.

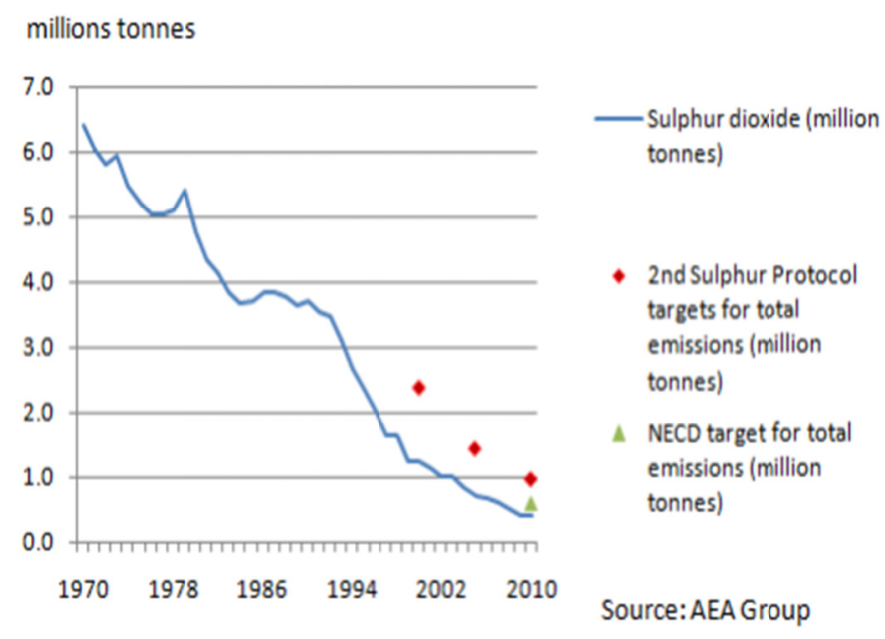

Figure 2. Emissions of Sulphur dioxide in UK (1970 - 2010)

Non-methane volatile organic compounds emissions: As illustrated in Figure 3, the emissions of non-methane compounds were decreased by $71 \%$ between the years 1990 and 2010 . Similarly, it was decreased by $4 \%$ between the years 1990 and 2010. 2010 was the year in which emissions were reduced to the standard target by $34 \%$.

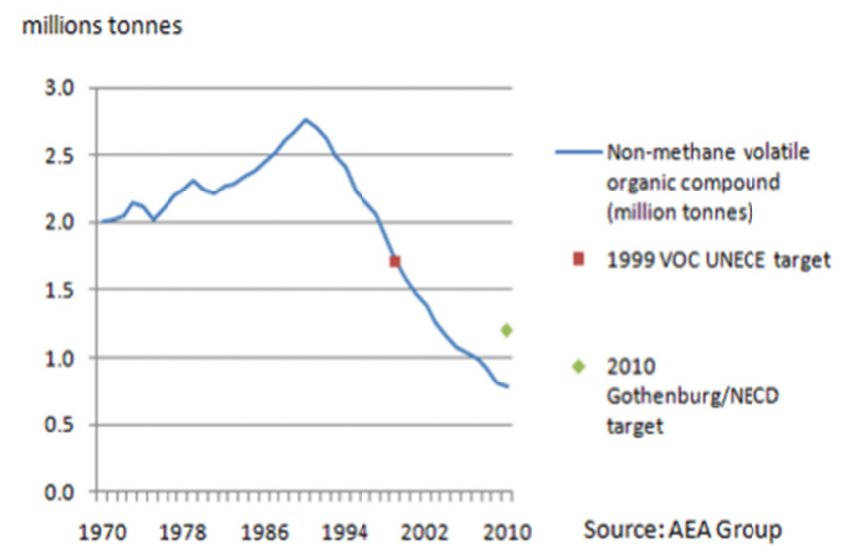

Figure 3. Emissions of methane compounds in UK (1970 - 2010)

Nitrogen oxides emissions: As illustrated in Figure 4, the emissions of nitrogen oxides were decreased by $62 \%$ 
between the years 1990 and 2010. At the same time, it was decreased by 3\% between 2009 and 2010and 2010 was the year in which emissions were reduced to the standard target by $5 \%$.

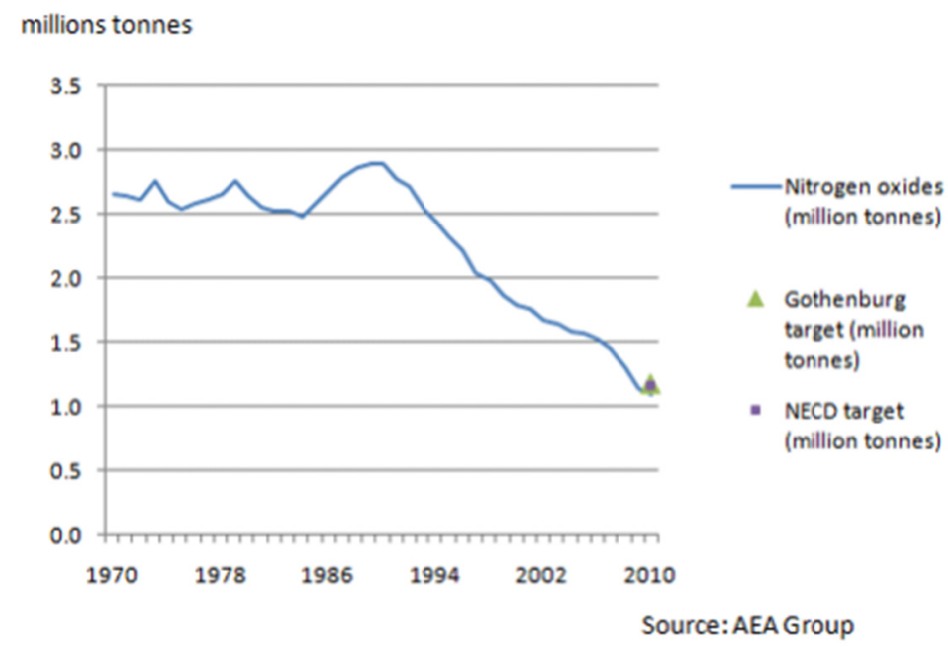

Figure 4. Emissions of nitrogen oxides in UK $(1970-2010)$

Considering the above findings, the emission of atmospheric gases have shown a vast decrease in UK, which is a good sign for the reduction in environmental pollution. The achievement of justifiable eco-development can be done by the implementation of Green Economy. There have been several factors that can feed the development of green products, which are as follow:

Atom Economy: In order to maximize the incorporation of all materials, synthetic methods should be designed in the process of making the final product.

Prevention: The prevention of wastes should first be implemented prior to the creation, rather than recycling the waste.

Safer Chemicals Designs: The chemicals should be designed in a way in which they produce less toxicity.

Energy Efficient Designs: Economic impacts should be minimized by recognizing the energy requirements for the chemical processes.

Safer Solvents: It should be integrated in the products, which are used by the workers and the atmosphere.

Degradation of Products: The products should be designed in such way so that they can be broken down into harmless degradation products and get removed from the environment, once they have been consumed.

Safer Chemistry: Reduce the potential of chemical accidents from the intelligent making of products.

These are some of the suggested ways, which can be resulted in the greener world (Valavanidis, 2012). Green economy has been adopted by the pharmaceutical and chemical industries to employ technological developments. This is because they provide sustainability, energy efficiency, and less toxic chemicals. The political and environmental legislation authorities have focused on the adoption of green economy because they provide safer products.

\subsection{Reduction in the misuse of limited resources}

Misuse of the limited resources, mainly include nuclear, coal, metal ores, natural gas, and oil, are those resources, which take a longer time to recreate. As it was observed in Zoboli, et al. (2014), the roadmap to Resource Efficient Europe was established in the year 2011 for 2020, which set different objectives such as the elimination of environmentally harmful subsidies, sustainable production and consumption, ecosystem services, food and drink, marine resources, mobility, and wastes (Zoboli, R., et al., 2014). 
Table 1. World's 5 fastest-growing economies. Annual average growth percent

\begin{tabular}{lclc}
\hline & $\mathbf{2 0 0 1 - 2 0 1 0}$ & & $\mathbf{2 0 1 1 - 2 0 1 5}$ \\
\hline Myanmar & 10.3 & Ethiopia & 8.1 \\
Kazakhstan & 8.2 & Tanzania & 7.2 \\
Chad & 7.9 & Vietnam & 7.2 \\
Cambodia & 7.7 & Ghana & 7.0 \\
Rwanda & 7.6 & Nigeria & 6.8 \\
\hline
\end{tabular}

Table 1 illustrated the fastest growing economies, and Africa was listed as the lowest resourced country. The exploitation of resources generated economic benefits in the short term (Mowforth \& Munt, 2015). The green economy will be helpful to the list of countries, who have scarce resources; similarly, appropriate use of such resources will be in the benefits of these countries. Each individual should be participating in the activities that will lead to the proper utilization of scarce resources. The country will prosper if every citizen plays a significant role in the less wastage of products and reuse the products if possible. Government bodies have their own roles regarding the efficient use of resources so that the healthy environment can prevail.

There are some factors that are needed to be focused for developing the green economy. These factors include financing, streamlined government services, improvement/continuation of government programs, market development, and public awareness of green activities that put the greatest impact on business growth. Furthermore, there are five most common recommendations to improve the local business climate, which may include local business and economic development, green training and education, networking and collaboration, reduction of government red tape, and awareness of programs and green initiatives.

For example, the African countries are at serious juncture in their enhancement trajectories. The resource basis of several productive sectors, which were confronted with internal challenges of the insistent unemployment and poverty are experiencing threats of the soil erosion, deforestation, and loss of biodiversity, effect of climatic changes and reduction of fish stocks. Simultaneously, these threatening challenges represent some opportunities for the change as well (Voumik \& Shah, 2014). South Africa is playing well to position itself as the fastest growing economies in the world. This country is not only rising in terms of the environmental aspect but also by the economic benefits of green building and attaining a sustainable approach (Growing, 2015). The rapidly increasing cities such as the Sub-Saharan Africa require to consider urgently the significance of the green economies and related assets as a part of their wider infrastructure development programmes. This can only be done when the accounting systems and city budgeting recognizes the value of the ecosystem assets offered by the green assets (Schäffler \& Swilling, 2013).

Recent publications on green growth by the United Nations Conference on Trade and Development (UNCTAD), the United Nations Environment Program (UNEP), the World Bank, the International Labor Organization (ILO), the Global Green Growth Institute (GGGI) have addressed to the environmental problems. There is the emergent practice in the application and design of national green economy policies by developed and underdeveloped countries. These aspects can help to provide some insights regarding policy measures for green economy.

A study conducted by $\mathrm{Wu}$, et al. (2015) identified that the surface water of the ten main systems in China have experienced transitional pollution with conspicuous eutrophication issues in main lakes or reservoirs. It has been shown by the Ministry of Environmental pollution of China that underground water was faced by around 57\% monitoring sites across the cities in China, which were found extremely polluted. The increasing number of incidents of the industrial pollution, rural water pollution, over use of pesticides and outdated sewerage system also compromise the health of rural citizens in China. The drinking water could not use by 0.2 billion of the rural citizens according to the national standards. China, Africa and Brazil have been the fastest growing economies in terms of sustainability.

The advantages of the proposed model for green economy assessment with respect to the obtained results lies in the creation of model and its use. The creation of the green economy lies in the applicability of the particular country, Ease of customization, transparency as well as the multi-stake holders' investments. Whereas, the use of the green economy can be efficiently implemented by considering the time horizon, doing efforts for its proper maintenance, audience and the IP support. 


\section{Conclusion}

The green economy is beneficial for each countries' economy, as it has shown substantial growth in the social, economic and environmental sectors. The study has shown the economic development of green economy across the globe. It has also provided with the better ways and ideas to eradicate environmental pollution, and reduce the misuse of limited resources. Green growth strategies have shown greatest progress in the analysis, implementation, planning, and monitoring processes of manufacturing. Robust planning have always been provided by the green economy. Such studies, which have been conducted up till now, have shown less adequate transformation of societies into the green economy. Future studies should involve the additional attention on the adoption of green economies to increase the economic status. Moreover, such techniques should be implemented that result in the better interests of humans and living things. Green growth practice assessment has provided the firm foundation for the legislations of political and environmental sectors with the inspiring examples of green growth. Acting in accordance with the green growth practice can be essential for the economic, social, and ecological growth of the countries. Therefore, it has been concluded that the green economy is helpful for decreasing the level of pollution along with the misuse of limited resources across the globe.

\section{Acknowledgement}

The author is very thankful to all the associated personnel in any reference that contributed in/for the purpose of this research. Further, this research holds no conflict of interest and is not funded through any source.

\section{References}

Coalition, G. E. (2012). The green economy pocketbook: the case for action. Retrieved October, 19, 2013.

de Oliveira, J. A. P., Doll, C. N., Balaban, O., Jiang, P., Dreyfus, M., Suwa, A., ... \& Dirgahayani, P. (2013). Green economy and governance in cities: assessing good governance in key urban economic processes. Journal of Cleaner Production, 58, 138-152. https://doi.org/10.1016/j.jclepro.2013.07.043

Growing, G. B. I. (2015). Green building rapidly taking hold in South Africa. Environmental Management. http://dx.doi.org/10.4172/2168-9768.S9-e001

Jacobs, M. (2012). Green growth: economic theory and political discourse. London: Centre for Climate Change Economics and Policy Working Paper No, 108.

Lean, G. (2006). Our Planet: The magazine of the United Nations Environment Programme.

Mowforth, M., \& Munt, I. (2015). Tourism and sustainability: Development, globalisation and new tourism in the third world. Routledge.

Nica, E. (2015). Green Economy and Sustainable Development. Agricultural Management Strategies in a Changing Economy, 337. https://doi.org/10.4018/978-1-4666-7521-6.ch015

Ocampo, J. A. (2011). The transition to a green economy: benefits, challenges and risks from a sustainable development perspective: summary of background papers. In Report by a Panel of Experts to Second Preparatory Meeting for United Nations Conference on Sustainable Development, Division for Sustainable Development UN-DESA, UNEP, UN Conference on Trade and Development, New York.

Schäffler, A., \& Swilling, M. (2013). Valuing green infrastructure in an urban environment under pressure-The Johannesburg case. Ecological Economics, 86, 246-257. https://doi.org/10.1016/j.ecolecon.2012.05.008

UNEP. (2014). Using Models for Green Economy Policymaking.

Valavanidis, A. (2012). Green Chemistry and New Technological Developments. New Avenues for the Green Economy and Sustainable Future of Science and Technology.

Valipour, M. (2012a). A comparison between horizontal and vertical drainage systems (include pipe drainage, open ditch drainage, and pumped wells) in anisotropic soils. IOSR J Mech Civil Eng, 4(1), 7-12. https://doi.org/10.9790/1684-0410712

Valipour, M. (2012b). Hydro-module determination for vanaei village in Eslam Abad Gharb, Iran. ARPN J. Agric. Biol. Sci, 7(12), 968-976.

Valipour, M. (2013a). Evolution of irrigation-equipped areas as share of cultivated areas. Irrig. Drain. Syst. Eng, 2, e114. https://doi.org/10.4172/2168-9768.1000e114

Valipour, M. (2013b). Use of surface water supply index to assessing of water resources management in Colorado and Oregon, US.

Valipour, M. (2013c). Increasing irrigation efficiency by management strategies: cutback and surge irrigation. 
ARPN Journal of Agricultural and Biological Science, 8(1), 35-43.

Valipour, M. (2013d). Necessity of irrigated and rainfed agriculture in the world. Irrig Drain Sys Eng. S, 9 , e001.

Valipour, M. (2015a). Future of agricultural water management in Africa. Archives of Agronomy and Soil Science, 61(7), 907-927. http://dx.doi.org/10.1080/03650340.2014.961433

Valipour, M. (2015b). Land use policy and agricultural water management of the previous half of century in Africa. Applied Water Science, 5(4), 367-395. https://doi.org/10.1007/s13201-014-0199-1

Valipour, M. (2016a). How do different factors impact agricultural water management?. Open Agriculture, 1(1). https://doi.org/10.1515/opag-2016-0014

Valipour, M. (2016b). How Much Meteorological Information Is Necessary to Achieve Reliable Accuracy for Rainfall Estimations?. Agriculture, 6(4), 53. https://doi.org/10.3390/agriculture6040053

Voumik, L. C., \& Shah, M. G. H. (2014). A green Economy in the Context of Sustainable Development and Poverty Eradication: What are the Implications for Bangladesh?. Journal of Economics and Sustainable Development, 5(3), 119-131.

Wu, L., Qi, T., Li, D., Yang, H., Liu, G., Ma, X. Y., \& Gao, J. E. (2015). Current status, problems and control strategies of water resources pollution in China. Water Policy, 17(3), 423-440. https://doi.org/10.2166/wp.2014.018

Zoboli, R., Miceli, V., Paleari, S., Mazzanti, M., Marin, G., Nicolli, F., ... Speck, S. (2014). Resource-efficient green economy and EU policies. Resource-efficient green economy and EU policies, (2), 1-107.

\section{Copyrights}

Copyright for this article is retained by the author(s), with first publication rights granted to the journal.

This is an open-access article distributed under the terms and conditions of the Creative Commons Attribution license (http://creativecommons.org/licenses/by/4.0/). 